УДК $78.01+781.6$

\author{
К. Майденберг-Тодорова
}

\title{
ЭСТЕТИЧЕСКАЯ ЗНАЧИМОСТЬ КОМПОЗИТОРСКОГО ЗАМЫСЛА В АЛЕАТОРНО-СОНОРИСТИЧЕСКОЙ КОМПОЗИЦИИ Д. КУРЛЯНДСКОГО «БЕСПРОВОДНЫЕ ТЕХНОЛОГИИ»
}

\begin{abstract}
Статья посвящена изучению проблемных текстовых и интерпретативных аспектов современного музыкального творчества. На примере «Беспроводных технологий» Д. Курляндского раскрывается взаимодействие специфических композиторских средств и авторской эстетической концепции в рамках современной алеаторно-сонористической композиции.
\end{abstract}

Ключевые слова: алеаторно-сонористичекая композиция, «периферийные звуки», артикуляционный тематизм.

Современное композиторское творчество тяготеет не только к созданию новых музыкальных форм, но и к интерпретированию устоявшихся представлений о музыкальном формообразовании как об объективной действительности музыки, к интерпретированию имманентной звуковой материи музыки и музыкальной материи звуковой реальности. Наиболее ярким отображением данной тенденции является алеаторно-сонористическая композиция - тип современной композиторской поэтики, выступающий в оппозиции к академически-традиционному музыкальному произведению. Используя новые формы звукоизвлечения, нотации, меняя хронотопические рамки произведения, современная музыка вынуждена прибегать к теоретическим положениям, обобщениям, объясняющим идею композитора, его мировоззрение, зачастую для каждого произведения в отдельности, так как нередко сам композитор, находящийся в поисках самобытности и оригинальности, адекватности способов самовыражения в музыке, меняет позицию по отношению к собственному творчеству.

Каждое новое произведение, создающееся в контексте алеаторносонористического направления современной музыки, представляет собой отдельный диалект музыкального языка, так как творческое индивидуальное мышление композитора стремится освободиться от общепринятых языковых структур, тяготеет к неповторимости. Отсюда - плюрализм текстовых обозначений, расхождение в пони- 
мании исполнителями заданных автором текстовых символов. Произведение оказывается в известной мере закрытым в собственной знаковой структуре, содержащим присущие только ему комплексы понятий, представлений, посредством которых происходит связь произведения со слушателем.

Современные композиторы в своих произведениях все чаще склоняются к выбору средств, которые являются «опосредованно музыкальными». М. Бонфельд называет их «периферийными», то есть такими, которые лежат за пределами музыкальных звуков или пришли из внемузыкального, бытового пространства - это шумы, стуки, скрипы и другие звуковые эффекты.

М. Бонфельд пишет о том, что музыкальный материал являет собой организованную композитором звучащую материю, то есть все то, что звучит и паузирует в процессе реального или воображаемого исполнения музыкального произведения. Также он указывает на то, что в настоящее время в окружающей реальности нет таких проявлений звучания и тишины, нет таких искусственных или естественных звуков, которые в той или иной форме не могли бы оказаться компонентами музыкальной речи. Следовательно, в самой звуковой атмосфере не существует границ между музыкальным и внемузыкальным [3, с. 77].

Привлечение немузыкальных звуков расширяет арсенал музыкально-выразительных средств композитора, позволяет искать и находить эквиваленты этих звуков посредством изобретения нетрадиционных приемов игры на музыкальных инструментах, а нередко и изобретения самих инструментов. «Любой фактор звуковой реальности становится компонентом музыкальной речи и наделяется художественным (идеально-духовным) смыслом, входя в целостный знак-произведение музыкального искусства, чем и отличается от неопосредованной звуковой реальности» [3, с. 77]. «Будучи частью внемузыкальной реальности, упомянутый звуковой фактор, входя в качестве компонента в художественно-музыкальную речь, представляет (репрезентирует) и ту внемузыкальную реальность, из контекста которой он извлечен, напоминая о ней, вызывая ее «эхо» в воспринимающем сознании» [3, с. 78]. Таким образом, знаковая система музыкального языка обогащается «периферийными звуками». По М. Бонфельду, периферия - это звучания, в которых принимают участие все немузыкальные звуки - стуки, шумы, гулы, скрипы, звуки, которые в течение длительного времени либо вовсе не включались в музыкальную ткань, либо играли в ней незначительную роль [3, с. 78]. 
Периферийная область звучания открыла новые возможности нотирования, которые стали новыми знаковыми сочетаниями, открывающими множество смысловых вариантов их понимания.

М. Бонфельд отмечает, что музыкальное произведение, взятое в целом, «обладает уникальным, характерным смыслом, который присущ только данному творению и инвариантен по отношению к любому контексту» [3, с. 18]. Это и есть выражение содержания произведения, его смысла. М. Бонфельд указывает, что «музыкальные произведения не выделяют таких единиц - знаков, которые вне контекста, как слова естественного языка, сохраняют устоявшееся единство означающего - означаемого» [3, с. 17].

Семантические особенности знаковой системы современного музыкального языка еще не выявлены в достаточной степени. Поэтому каждый слушатель подсознательно или осознанно вырабатывает собственную стратегию восприятия и понимания данной музыки. Опытный слушатель стремится достраивать контекстные условия для звучащего текста. Если слушатель уже достаточно включен в данную знаковую сферу, то он осознанно (а чаще - неосознанно) включает прослушанный фрагмент в знакомый контекст, и тогда в его сознании формируется означаемое, связанное не только с этим фрагментом, но и с тем контекстом, куда он входит как часть музыкального произведения. Возможно, что слушатель «дорисовывает» в воображении существенный для данного фрагмента контекст, если фрагмент ему незнаком, но обладает яркими признаками известных стиля, жанра и иных, порождающих контекст, факторов. Если услышанный фрагмент не только неизвестен, но к тому же настолько нов и необычен, что не в состоянии вызвать в слушательском воображении соответствующий контекст, он не будет воспринят как художественно содержательная музыка.

Обращение к периферийным звукам все чаще встречается в современных алеаторно-сонористических партитурах. Они располагаются в общей точке взаимодействия алеаторных и сонористических приемов, ведущих к новому типу музыкального тематизма. Артикуляционный тематизм становится новым формо- и смыслообразующим условием алеаторно-сонористической композиции. В его основе лежит сам процесс артикулирования, то есть акт произношения исполнителем структурно-семантических элементов композиторского текста. В артикуляционном тематизме звуковысотные и ритмические параметры могут полностью отсутствовать. В качестве выразительных композиторских средств отдается предпочтение «периферийным», 
то есть внемузыкальным средствам и звучаниям. Неизменным признаком артикуляционного тематизма становится специфический тип письменной фиксации, для которой традиционный нотный стан не является обязательным. В соответствии с намерением композитора интонационные, а иногда и ритмические, решения такого тематизма множественны и создаются исполнителем при каждом новом исполнении заново, следовательно, содержат в себе импровизационность.

Творчество Дмитрия Курляндского не является исключением, a, скорее, подтверждает отношение к «периферийному звуку» как к эстетическому объекту. Свою эстетическую концепцию он определяет как «аннарративную», то есть такую, которая находится в оппозиции с «нарративной». Для композитора «нарратив - это последовательное повествовательное измерение, которое идет из точки А в точку Б через череду каких-то событий и по дороге меняется. Это «авторский нарратив, когда автор (неважно - композитор или нет) излагает в звуках, в искусстве с которым он имеет дело, некую последовательность (очередность) событий» [1].

Под «аннарративом» Д. Курляндский подразумевает «ситуацию, где автор создает некое пространство, некую ситуацию, в которой оставляет слушателя одного, и в которой слушатель волен самостоятельно выстроить свой собственный нарратив по отношению к той ситуации, которую автор ему предложил» [1]. «Нарратив родится в слушателе в любом случае»... «история, которая может родиться в слушателе, индивидуальна, построена на его личном опыте, она может войти в конфликт с нарративом, который я предлагаю слушателю как автор», уточняет композитор [1].

Претворение данной авторской концепции мы можем проследить, обратившись к камерному произведению Д. Курляндского «Беспроводные технологии», написанному для голоса и трех инструментальных составов, на поэтический текст нашего современника Станислава Львовского.

По словам композитора, данное произведение создавалось для берлинского фестиваля поэзии. Исполнение должно было проходить на лестничной клетке Академии искусств Берлина, именно поэтому родилась идея пространственной композиции. «Я разбил этот текст на пиксели-фонемы и перемешал их среди исполнителей» [5].

Несмотря на стремление к «аннарративности», отношение к словесному тексту и к собственному музыкальному тексту, его реализация в пространстве и во времени тщательно выверены и конструк- 
тивно продуманы композитором. Его волнуют мельчайшие детали, о которых мы можем узнать, прочитав «легенду», то есть послание автора к исполнителям.

В авторском предисловии большое внимание уделено пространственным параметрам произведения: три группы ансамбля должны быть размещены в пространстве концертного зала так, чтобы все музыканты третьей группы и, как минимум, один музыкант в первой и второй группах могли видеть исполнителя партии голоса. Расстояние между группами зависит от акустических условий - все музыканты должны быть хорошо слышны. Партия голоса, по желанию, может быть подзвучена с помощью четырех (или более) динамиков, рассредоточенных по залу. Громкость динамиков должна быть приближена к живому звучанию голоса. Аудитория может располагаться вокруг и между группами исполнителей.

Д. Курляндский. «Беспроводные технологин»

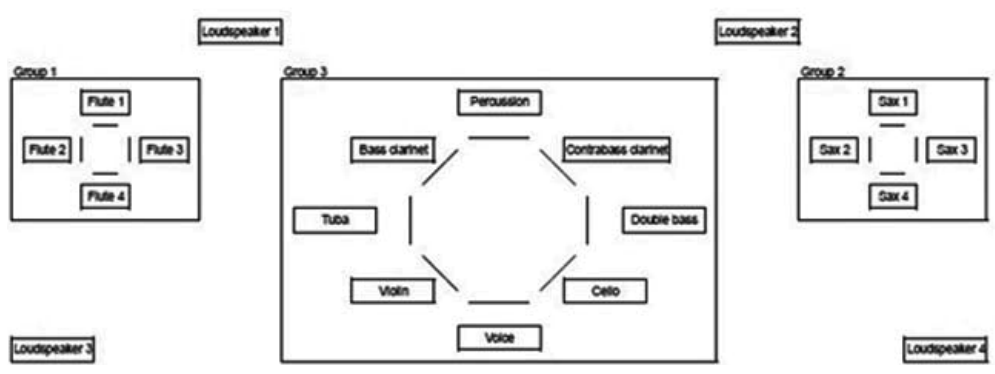

Отношение ко времени произведения также регламентируется композитором. Структура произведения такова, что первый ее раздел исполняют две группы музыкантов - группа флейт и группа саксофонов. Во втором разделе к ним присоединяются исполнитель партии голоса и окружающие его партии струнных, духовых и перкуссионных инструментов. Начало разделов регламентируется исполнителем партии голоса: он показывает первой и второй группам время вступления, а также окончания исполнения. Вся композиция исполняется без дирижера.

Первый раздел подчинен принципу алеаторики - секции исполняются в свободном порядке, а не в строго записанной последовательности. Каждый раз, когда исполнитель приближается к указанному знаку, ему следует перейти на другую секцию, выбранную им. Секции могут повторяться. 

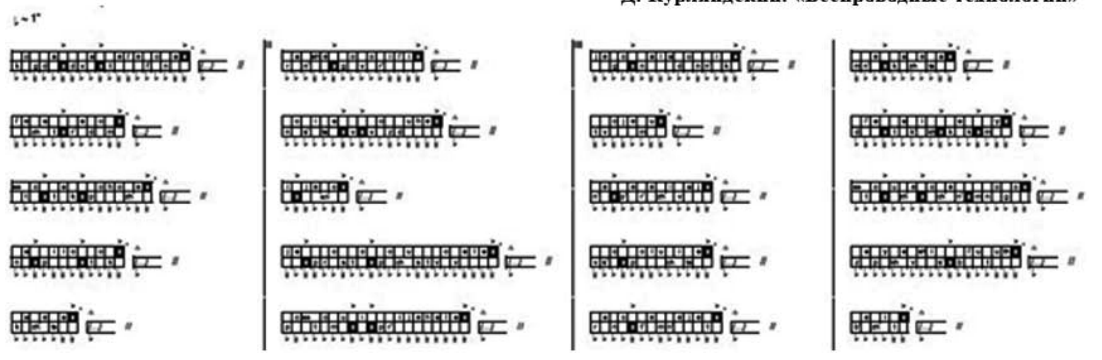

Интересно проследить отношение композитора к нотации. Мы можем наблюдать полный отказ от пятилинейного стана. Отношение к звуку как к самобытному явлению, как к результату произношения (артикулирования) продиктовало такой способ авторской графической нотации, в которой отражено лишь динамическое и артикуляционое начало. Для разных видов инструментов (струнных, духовых, ударных) одни и те же графические обозначения подразумевают различные способы артикулирования, в зависимости от специфики инструмента. Динамика обозначена прямоугольниками, закрашенными соответственно силе звука - не закрашенный прямоугольник - p, серый - mp, черный - mf. Каждый из обозначенных композитором исполнительских знаков не фиксирует определенную звуковысотность, а указывает лишь прием исполнения: звучание не регламентировано и может каждый раз представать иным.

Д. Курляндский. «Беспроводные технологии»



Композитор не пользуется звуковысотностью, именно поэтому отказ от пятилинейного нотного стана является вполне осознанным. Он заинтересован, прежде всего, в раскрепощенном звуке, то есть в соноре. Данное раскрепощение находится на пересечении алеаторной и сонористической техник музыкального письма, что позволяет 
расширить хронотопические рамки произведения. Д. Курляндский считает, что «у каждого звука есть жизнь, нарративное развитие, у каждого звука есть третье измерение - перспектива этого звука» [1].

Так же как со звуком, Д. Курляндский обращается и со словесным текстом. «Имея дело с текстом, я исхожу из того, что в нем уже заложена музыка - подобно тому, как звук заложен в нас. Не только в тексте произнесенном, но и в тексте графическом. Буква - знак, мы вольны назначать ему значения. Букву можно не только произнести вслух, но и начертить на мембране барабана или на другой поверхности, «наскрести» смычком на струнах. В то же время, буква произнесенная - есть артикуляция, звуковое событие. Ее можно произнести в инструмент, который придаст ей свою характерную акустику» [2]. Он находит в нем сонор, фонему, которую извлекает и превращает в музыкально-артикуляционный прием, предназначенный не только для исполнителя партии голоса, но и для исполнителей на духовых инструментах. Флейты и саксофоны исполняют предложенные им артикуляционные фонемы без мундштуков - «губами в инструмент». «Текст в музыке становится звуком - значит работать с ним можно как со звуком. И задача - чтобы этот звук открывал при этом пути к новым значениям текста, к новым перспективам и смыслам» [2].

Особого внимания заслуживает партия голоса. Исполнитель этой партии не является ни певцом, ни чтецом. Это довольно монотонный монолог-диалог - то ли по мобильному телефону, то ли по какомулибо другому беспроводному гаджету - с неизвестным нам вторым персонажем. А также это монолог-диалог с самим собой, так как партия голоса разделена на два полифонических пласта. Каждое слово и словосочетание проговаривается, а затем произносится артикуляционно-фонетически - на вдохе, на выдохе, щелканием языка, гортанными звуками. Данному внутреннему диалогу предшествует внутренний монолог, текст которого произносится с закрытым ртом. Таким образом, можно представить данную диалогичность как противопоставление двух сфер - реальной - разговор человека по телефону, и виртуально-цифровой - передача этой информации по воздуху - то есть во времени-пространстве.

Если мы обратимся к литературному первоисточнику, то заметим, что стихотворение написано без единого знака препинания. Между строфами присутствуют разделительные знаки, что может служить подсказкой к обращению с данным текстом как с открытым. Именно это мы можем заметить в композиторском прочтении текста. 
У С. Львовского стихотворение завершается описанием бытовой реальной семейной ситуации: «я на самом деле/ злюсь/ когда ты в магазине/ отказываешься отвечать/ какой купить йогурт/ на завтрак/ злюсь/ потому что боюсь/ выбрать тот/ который тебе/ не понравится» [4]. В вариантном прочтении Д. Курляндского три последние строфы перенесены в начало и исполняются закрытым ртом, превращая живое обращение героини к скрытому для нас герою в монологичные высказывания героини «внутри себя». Остальная часть стихотворения в результате перестановок приведена к тому, что произведение заканчивается в смысловой кульминационной зоне. Последовательно выстроенный композитором алгоритм нарастающей звучности в партиях инструментальных составов и все более напряженное произношение текста голосом неожиданно обрывается, и на фоне тихого звучания алеаторно-сонористического материала первой и второй духовых групп, как в озвученной тишине, произносится многозначительная фраза - «иногда думаешь/ может и правда/ попросить Его/ чтобы ну/ хоть как-нибудь/ а потом/ понимаешь нет/ такая толпа/ с нашим gprs/ хиленьким/ никаких/ шансов» [4].

Итак, основная идея произведения заложена в программном названии «Беспроводные технологии». Данный заголовок уже требует не столько словесной конкретики, сколько образно-сонористического окрашивания, опространствования данной идеи. Благодаря вышеперечисленным композиторским приемам постепенно обнаруживается единство программного замысла и его композиционного звукового воплощения. Данное произведение создает эффект передачи информации по воздуху от одной точки к другой, в частности, от исполнителя к слушателю. Голос озвучивает то цельную фразу, то ее дискретное фонетическое повторение, как бы подражая рассеиванию в пространстве переданного послания по мобильному устройству, а инструментальный ансамбль создает эффект помех и радиоволн. Кроме этого, в произведении озвучивается актуальная в наше время проблема одиночества и разобщенности людей, которой парадоксальным образом способствуют развитие технологий и возможность быть на связи в пределах любого пространства в любое время.

Благодаря воплощенному Д. Курляндским новому пониманию формы и материала музыкального произведения предметом восприятия и оценки становится, прежде всего, эстетическая, а затем уже технологическая сторона алеаторно-сонористического замысла. Художественная целостность звучащей композиции, которая связа- 
на с раскрепощением ее хронотопических параметров, открывается постепенно и последовательно, а осознание идеи произведения приходит уже после его завершения, которое заставляет продолжать размышление над смыслом услышанного. В этом, видимо, и заключается запланированное композитором «аннарративное» воздействие алеаторно-сонористической композиции; она вызывает особое когнитивное напряжение и превращает восприятие музыки в процесс интеллектуальной реконструкции и семантического декодирования, таким образом - достраивания, художественного текста.

Произведение Д. Курляндского «Беспроводные технологии» представляется убедительным примером алеаторно-сонористической композиции, в которой соединение алеаторики и сонористики приводит к открытию новых свойств текста, в частности, к применению артикуляционного тематизма не только в инструментальных партиях, но и в партии голоса. Все перечисленные средства в комплексе работают на раскрытие программного замысла композитора, на создание целостной художественной концепции произведения, которая завершает свое формирование в интерпретативном сознании слушателя.

\section{СПИСОК ЛИТЕРАТУРЫ}

1. Амрахова А. Дмитрий Курляндский. Об одном из 158 способов структурирования времени и пространства [Электронный ресурс] / А. Амрахова // Harmony : Международный музыкальный культурологический журнал / [гл. ред. Т. Мамедов]. - 2013. - № 12. - Режим доступа к журн. : http://harmony. musigi-dunya.az/rus/reader.asp?s $=1 \&$ txtid $=518$

2. Бавильский Д. Дмитрий Курляндский: «Я не придумываю, я думаю...» [Электронный ресурс] / Д. Бавильский // Частный корреспондент : интернетгазета. - дата публикации 12.09.2012. - http://www.chaskor.ru/article/dmitrij_ kurlyandskij_ya_ne_pridumyvayu_ya_dumayu_29504 - Название с экрана.

3. Бонфельд М. Музыка: Язык. Речь. Мышление. Опыт системного исследования музыкального искусства / М. Бонфельд. - СПб. : Композитор, 2006. $-648 \mathrm{c}$.

4. Львовский С. Беспроводные технологии [Электронный ресурс] / С. Львовский // По непрочному воздуху. По следам ХІ Московского Фестиваля верлибра : альманах / [сост. Д. Кузьмин]. - М. : АРГО-РИСК; Тверь : Колонна, 2004. - Режим доступа: http://www.vavilon.ru/metatext/neprochno/ lvovsky.html

5. Северина И. Современная музыка. В режиме мозгового штурма [Электронный ресурс] / И. Северина // Играем с начала. Da capo al fine : интернетгазета / [гл. ред. И. Евард]. - 2014. - № 10 (125). - Режим доступа: http:// gazetaigraem.ru/a4201203 
Майденберг-Тодорова К. Естетична значимість композиторського задуму в алеаторно-сонористичній композиції Д. Курляндського «Бездротові технолоziï». Стаття присвячена вивченню проблемних текстових та інтерпретативних аспектів сучасної музичної творчості. На прикладі «Бездротових технологій» Д. Курляндського розкривається взаємодія специфічних композиторських засобів та авторської естетичної концепції в рамках сучасної алеаторно-сонористичної композиції.

Ключові слова: алеаторно-сонористнчна композиція, «периферійні звуки», артикуляційний тематизм.

Maidenberg-Todorova K. Aesthetic significance of composer intention into D. Kuorliandski's aleatoric-sonoristic composition «Wireless technologies». The article is dedicated to studying of problem textual and interpretative aspects of contemporary music art. The interaction of specific composers tools and aesthetic conception of author within contemporary alestoric-sonoristic composition reveals in the example of D. Kuorliandski’s «Wireless technologies».

Key words: aleatoric-sonoristic composition, «peripheral sounds», articulation thematism.

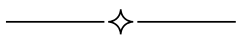

УДК $78.03+783.6$

\section{T. Каплун}

\section{ПРЕПОДОБНАЯ ЕВФРОСИНИЯ ПОЛОЦКАЯ В ДРЕВНЕРУССКОЙ ПЕВЧЕСКОЙ И ЖИТИЙНОЙ ТРАДИЦИИ}

В статье рассмотрены духовные и певческие аспекты воплощения образа святой Евфросинии Полоикой в древнерусской житийной и богослужебной традиции.

Ключевые слова: святость, житие святых, древнерусская певческая традиция, православное богослужение, Евфросиния Полоцкая, поэтика образа.

Евфросиния Полоцкая - один из самых светлых, тонких и чистых образцов древнерусской женственности, почитаемая святой преподобной как в православной, так и в греко-католической традиции. Святая дева, преподобная Евфросиния, основательница и первая игуменья полоцкого Спасо-Преображенского монастыря, инокиня и просветительница первой половины XII века, чья память приходится 